\title{
On the Identification of Local Structural Defects in Composite Thin-Walled Structures
}

\author{
Henryk Kopecki' ${ }^{*}$, Łukasz Święch', Radosław Kołodziejczyk¹ \\ 1 Department of Aircraft and Aircraft Engines, Rzeszow University of Technology, al. Powstańców Warszawy 12, \\ 35-959 Rzeszów, \\ * Corresponding author's e-mail: hkopecki@prz.edu.pl
}

\begin{abstract}
The presented work considers the issue of the usefulness of alternative methods aimed at quickly and effectively identifying the local damage to the thin-walled composite load-bearing structures. Two ways of identifying destruction were considered, based on the assumption that the damage that occurs during operation causes local changes in the system rigidity. The first method is based on strain gauges. It consists of embedding strain gauges in the structure at the stage of composite production and monitoring of deformation during its life cycle. The second of the concepts under consideration is based on modal analysis, carried out using a modal hammer. On the example of the plate band, experimental studies supported by numerical analysis were carried out. The obtained research results and numerical analyses allowed for the formulation of a number of conclusions, mainly in terms of focusing on further research.
\end{abstract}

Keywords: thin-walled structures, composite structures, embedded strain gauge, modal analysis

\section{INTRODUCTION}

Composites are a category of engineering plastics characterized by a number of peculiar conditions related to the design process, manufacturing and verification tests. Wide possibilities of shaping the structure, as well as the possibilities of directing and differentiating the mechanical properties of the designed system are important attributes associated with composite structures [12].

These features promote the expansion of the applications spectrum of composite constructions. In particular, this applies to the thin-walled structures, increasingly often used as heavily loaded supporting structures. An example of this type of application are the elements of the aircraft airframe $[15,16,20]$.

Nowadays, determining the stress fields of the mentioned systems in the states of critical deformation on the basis of non-linear theories are becoming available $[2,8,14]$. Despite this, obligatory experimental studies during which it is expected to confirm compliance in the behavior of the real system with the constructor's assumptions, show the necessity of continuous improvement $[3,13,18,22,25,27]$.

Verification testing of the thin-walled structures is not easy to perform. They involve high-complexity equipment, require qualified service, and finally, the results obtained are highly dependent on the quality of the measuring devices. Therefore, the search for improved methods of research, in particular the studies of composite systems, is becoming a highly topical issue.

The local loads that occur during operation, causing hardly noticeable damage caused by accidental impact or collision of the structure with an obstacle (e.g. collision with a bird of the airframe structure during a flight, as well as improper maintenance) are dangerous to the thin-walled composite constructions. Thus, fast and effective repair becomes a necessity [19]. 
In this work, the usefulness of alternative methods for quickly identifying the damage to a thin-walled composite structure was analyzed. The considerations were limited to the analysis of two methods, i.e. the widely used method based on strain gauges and the method based on a modal analysis. It is assumed that any damage will change the stiffness of the body, which can be identifiable by experimental testing, relating them to the state of the reference $[6,21,24,26]$.

The strain gauge method widely used for monitoring strength parameters in damaged loadbearing structures is possible to use if load cells are built into the structure at the manufacturing stage. The task of the measuring system is to provide the right amount of information that is the basis for quick repairs. A similar task must be fulfilled by a concept based on a modal analysis implemented with an impact hammer [4, 17, 23]. The research was supported by a comparative numerical analysis.

The whole problem was considered on the examples of the plate band. The obtained results allowed formulating a number of conclusions, mainly in terms of directing further research with the perspective of wider applications.

\section{SCOPE AND SUBJECT OF THE RESEARCH}

In order to identify the local damage to the thin-walled composite structures, two methods were analyzed to determine the presence of damage.

The first method is based on the concept of embedding strain gauges between composite layers, located in various zones of the loadbearing structure. The changes in the stiffness of the system prove the existence of damage in the studied area.

a)

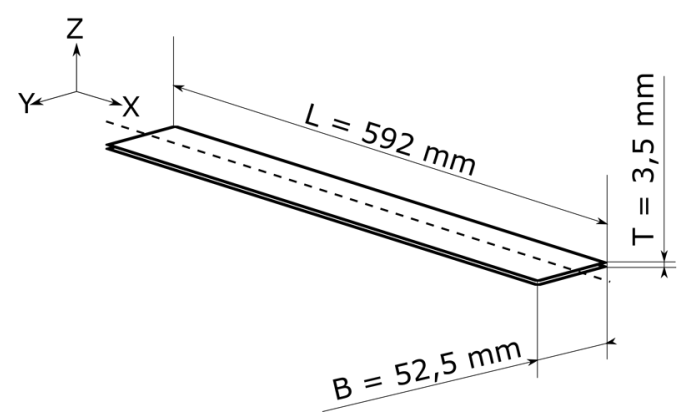

The second method is based on performing a modal analysis in the studied zones of the structure. It involves the excitation of the structure with a modal hammer and measurement of the system response with an acceleration sensor. The local changes occurring as a result of damage representative of the change in the rigidity of the system, are observed. They form the basis for identifying the presence of damage.

While the first method requires prior preparation of the zones subjected to potential tests at the stage of structure manufacture, the second method does not have such limitations. However, it requires creating a reference model by measuring the undamaged structure. Considering the issues related to the first method, attention was paid to its advantages, as well as to the disadvantages and limitations of the method. Both methods were supported by appropriate numerical analyses conducted in terms of the Finite Element Method (FEM).

The issues determining the usefulness of the considered concept are discussed on the example of the analysis of composite plate band made of 18 layers of bidirectional carbon fiber reinforced polymer (CFRP) with an area mass of $98 \mathrm{~g} / \mathrm{m}^{2}$ and fiber orientation $\pm 45^{\circ}$. The "vacuum bag" technology was used to produce the tested specimen. As a result, a structure with a length of $L=592 \mathrm{~mm}$, a width of $\mathrm{B}=52.5 \mathrm{~mm}$ and a thickness of $\mathrm{T}=$ $3.5 \mathrm{~mm}$ was obtained. The beam mass was $162 \mathrm{~g}$. The basic mechanical properties of the resulting composite are shown in Table 1.

For the needs of research, special HBM LI 66 strain gauges ( $10 \mathrm{~mm}$ base, $350 \Omega$ resistance) were integrated into the structure at the manufacturing stage. These strain gauges were placed between successive layers of the fabric forming the composite (Fig. 2), symmetrically in relation to the neutral axis of the band. They formed half-bridge systems, connecting the 3 rd and 15th layer strain

Fig. 1. Schematic of plate band, a) dimensions, b) fiber orientation 
gauges and the 5th and 13th layer strain gauges, respectively [11]. In addition, the general purpose strain gauges with a base of $6 \mathrm{~mm}$ and $120 \Omega$ resistances manufactured by Vishay were placed on the outside layer of the CFRP. In a plan view, the strain gauges were in the symmetry axis of the band around half of its length but were arranged so as not to overlap in order to avoid the local growth of thickness of the tested band.

The research object was created in the workshop of the Department of Aircraft and Aircraft Engines of Rzeszow University of Technology.

\section{EXPERIMENTAL RESEARCH}

\section{Static test with strain gauges}

During the experimental tests, the beam was subjected to four-point bending using a specially prepared test setup, which was mounted in the measuring space of the ZWICK Z050 testing machine (Fig. 3). The indications of strain gauges were recorded using an eight-channel QuantumX MX840B measuring amplifier controlled by CATMAN software (CATMAN EASY AP 3.5) from $\mathrm{HBM} \mathrm{GmbH}$.

The tests were carried out for three load levels of $7.5 \mathrm{Nm}, 10 \mathrm{Nm}$, and $12.5 \mathrm{Nm}$. As a result of the applied support system, a clean bending zone was created between the internal supports. Thus, it was possible to measure the deformation along the thickness, despite the fact that the position of the strain gauges was different along the length of the band. The distribution of this deformation is shown in Figure 4. The linear nature of the measured strains was preserved even after large deformation $[1,5]$. During the tests, the beam was not damaged.

Table 1. Mechanical properties of the composite

\begin{tabular}{|c|c|c|c|}
\hline $\mathrm{E} 11$ & $\mathrm{E} 22$ & $\mathrm{v} 12$ & $\mathrm{G} 12$ \\
\hline $\mathrm{GPa}$ & $\mathrm{GPa}$ & - & $\mathrm{GPa}$ \\
\hline 47,9 & 47,9 & 0,295 & 4,5 \\
\hline
\end{tabular}

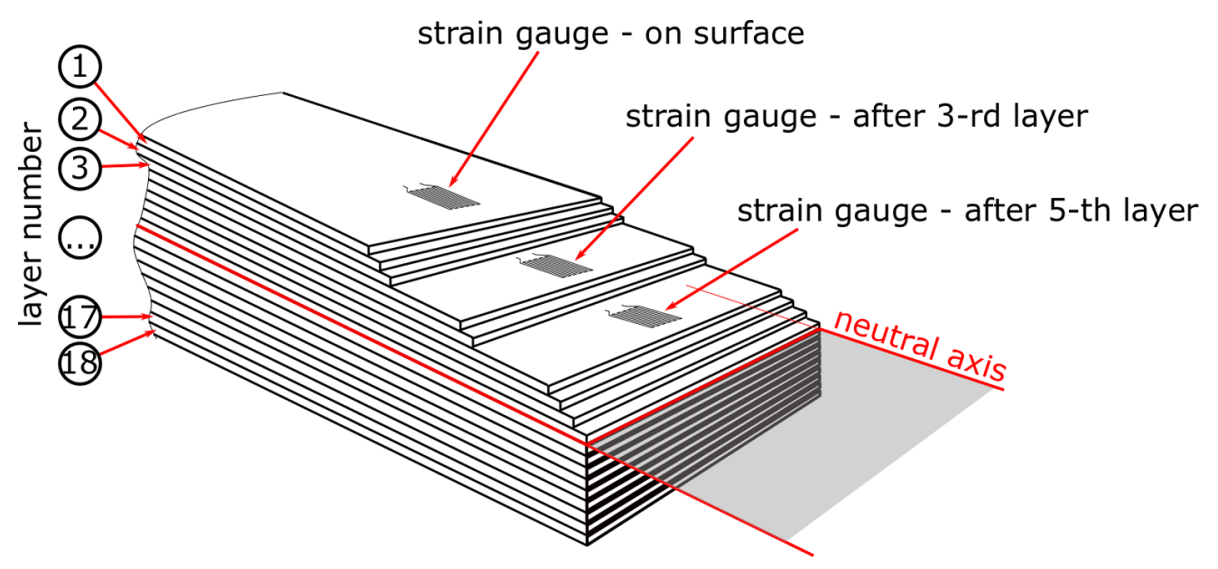

Fig. 2. Location of strain gauges in a composite strip
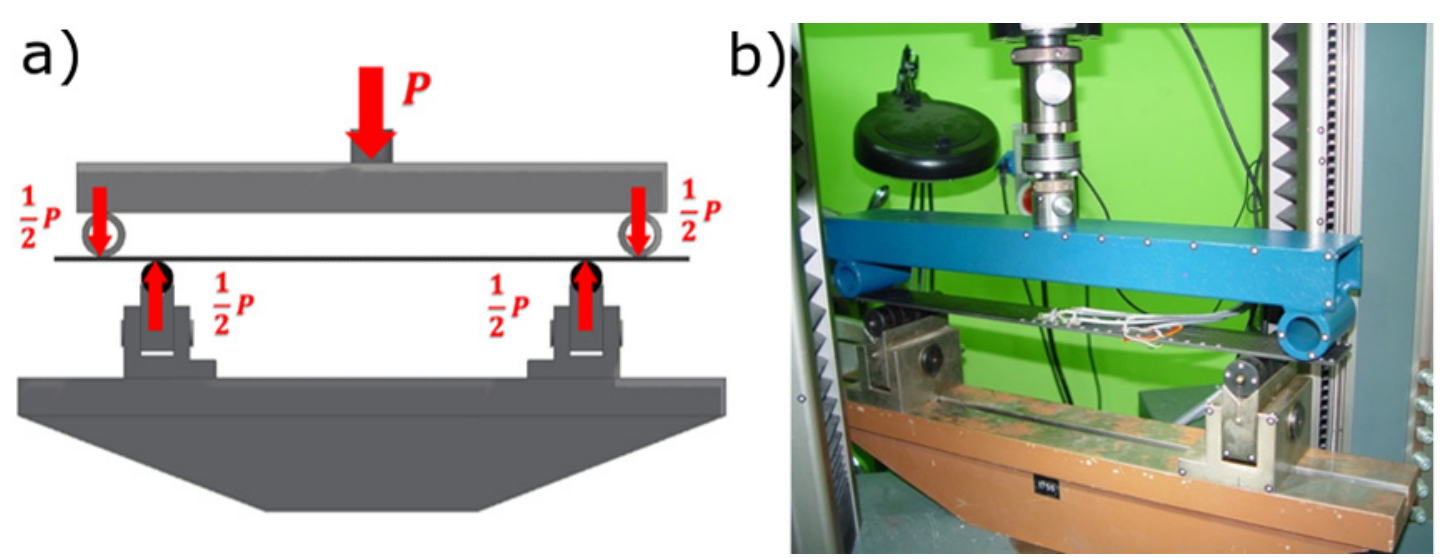

Fig. 3. Schematic of the loading system (a) and technical realization of a test stand (b) 


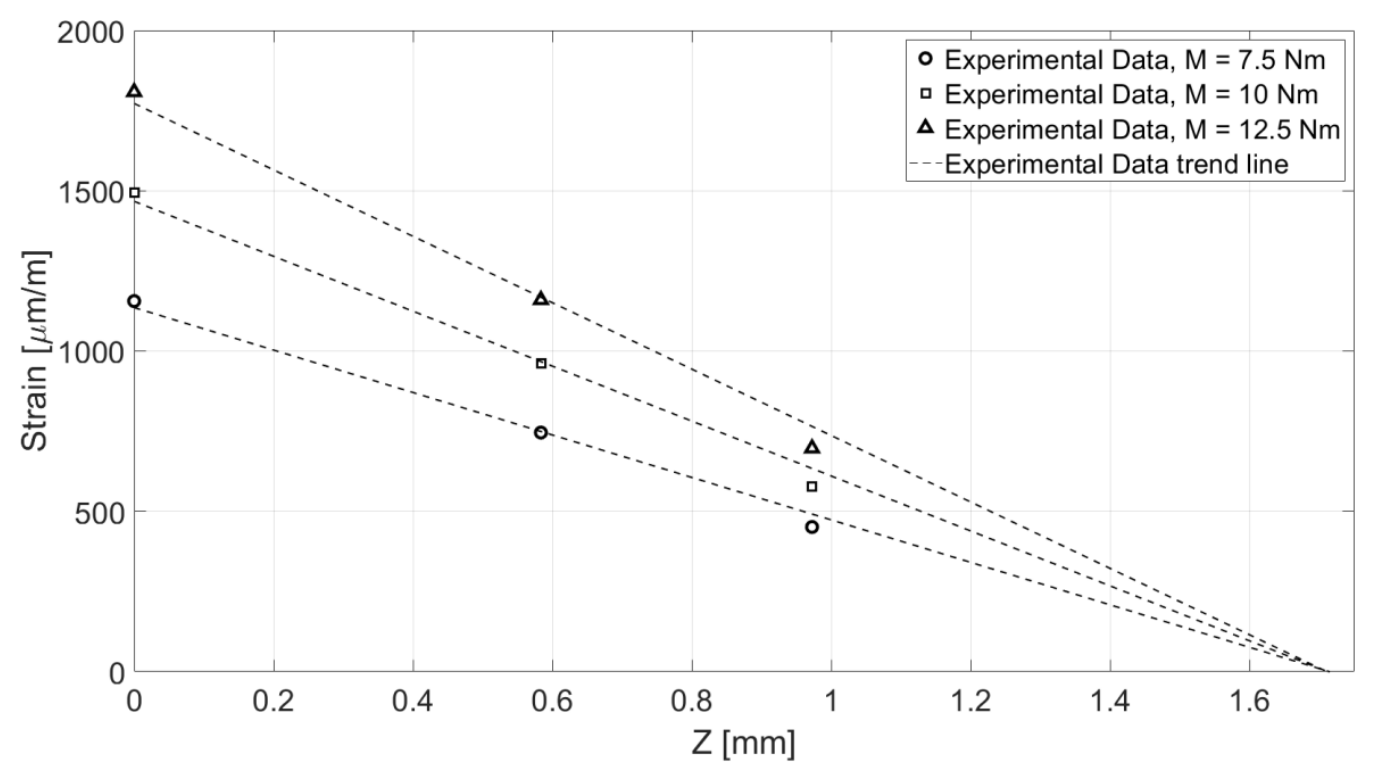

Fig. 4. Measured strain through thickness due to different bending moment values

\section{Research based on modal analysis}

The modal analysis is an integral part of the development and research of a wide range of support structures. It is a significant tool for defining and solving a number of structural dynamics problems, such as fatigue, vibration and noise $[9,17]$.

The conditions determining the possibilities of extending the scope of applications of the said method to identify local damage to thin-walled composite structures were considered. The analyzed concept is an attempt to broaden one of the most useful techniques for studying the frequency response of a structure based on the excitation of a structure using a modal hammer. In many situations, this is the simplest and fastest of the various techniques currently used.

Modal hammers are precision measuring tools. They come in many variants, differing in parameters such as mass, sensitivity, amplitude and frequency ranges, as well as size and shape. Owing to this diversity, it is possible to study a variety of objects, which translates into a significant number of specific applications.

The use of the method to identify the damage in the thin-walled composite systems boils down to a rational interpretation of the perceived quantitative and qualitative changes in the frequency response of the examined structure. This change is the effect of changing the rigidity of the damaged system. In the work, the damage identification was made by a quantitative comparison of natural frequencies and a qualitative comparison of mode shapes of the plate band with and without damage.

\section{Description of the method}

The method used in the research involves the excitation of the structure at defined points using a hammer with a built-in force sensor. The system response is recorded using an IEPE (Integrated Electronics Piezo-Electric) accelerometer. The relation between the excitation introduced into the system and its response is described by the frequency response function (FRF). It is determined by fast Fourier transform (FFT) of the registered input and output signals. The FRF function is described by the equation $[9,10]$ :

$$
\left[\begin{array}{c}
X_{1} \\
X_{2} \\
\vdots \\
X_{p}
\end{array}\right]=\left[\begin{array}{ccc}
H_{11} & \ldots & H_{1 q} \\
H_{21} & & \vdots \\
\vdots & & \vdots \\
H_{p 1} & \ldots & H_{p q}
\end{array}\right]\left[\begin{array}{c}
F_{1} \\
F_{2} \\
\vdots \\
F_{q}
\end{array}\right]
$$

Or in short form:

$$
\{X\}=[H]\{F\}
$$

Where: $X$ - system response,

$H$ - matrix of frequency response, frequency response function,

$F$ - excitation introduced to a system.

The natural frequencies are identified as peaks in the Frequency Response Function (FRF). A useful tool for determining them is MIF (Mode Indicator Function), calculated using dependencies [9]: 
$M I F=1-\left(\frac{\sum_{i, j=1}^{n} \operatorname{Re}\left(T F_{i j}(\omega)\right) \cdot\left|T F_{i j}(\omega)\right|}{\sum_{i, j=1}^{n}\left(\left|T F_{i j}(\omega)\right|\right)^{2}}\right)$

Where: $T F_{i j}(\omega)$ - transfer function in response point $\mathrm{j}$ due to excitation in i point,

MIF takes the values in the range $<0$ : $1>$, where the values close to 1 indicate the occurrence of the natural frequency.

One of the easiest ways to determine the mode shapes of the structure is to use a method called Quadrature Picking. Its basis is the assumption that the coupling between individual normal modes of vibration is light. Usually, this is associated with low damping of the structure. It gives the possibility to analyze individual mode shapes independently because they have no mutual influence or this influence is small. For the structures with low coupling of mode shapes, the value of the imaginary part of the FRF function corresponds to the modal displacement. By determining this modal displacement for each point where the structure was excited, the shape of the vibrations can be determined. This method of identifying normal mode shapes is schematically shown in Fig. 5.

\section{Description of the tests}

The issue is illustrated by the example of a plate band with identical material and geometrical properties that were used in the case of a static test. The band was fixed on one side in such a way that the free part was $500 \mathrm{~mm}$ long. Twelve points were marked on the band where the structure was excited with a modal hammer. The points were located at the edges of the band at $100 \mathrm{~mm}$ intervals, measured along the span. At a distance of

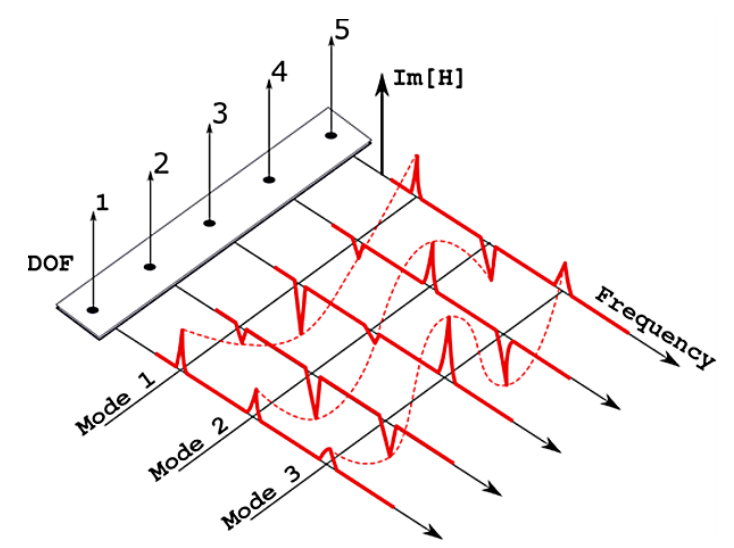

Fig. 5. Schematic of mode shape identification [7].
$50 \mathrm{~mm}$ from the free end of the band, in the axis of symmetry, an accelerometer measuring the structure response to the applied excitation has been placed. First, the band was examined without damage, then the damage was simulated by making a hole. The hole was located in the beam axis of symmetry at a distance of $150 \mathrm{~mm}$ from the fixed support. In subsequent tests, the hole was enlarged and the measurements repeated. Five measurements of the damaged beam were carried out for the holes with diameters of $3 \mathrm{~mm}$, $8 \mathrm{~mm}, 13 \mathrm{~mm}, 21 \mathrm{~mm}$ and $29 \mathrm{~mm}$.

A PCB Piezotronics hammer was used to excite the structure. The hammer has a built-in force sensor with a sensitivity of $2.25 \mathrm{mV} / \mathrm{N}$ and a range of $\pm 2224 \mathrm{~N}$. The acceleration measurement was made using an IEPE accelerometer from the PCB with a sensitivity of $10.65 \mathrm{mV} / \mathrm{g}$. The measurement results were recorded using a DEWESoft Sirius signal analyzer. The range of tested frequencies was set at $2500 \mathrm{~Hz}$ with the possibility of measuring 8192 levels, which resulted in a resolution of $0.305 \mathrm{~Hz}$. The diagram and technical implementation of the test stand is shown in Fig. 6. The location of the hole in the band is shown in Figure 7.

The Frequency Response Function was determined in the dedicated DEWESoftX3 software. The obtained results were then analyzed in the MatLab software. The location of the nodal lines was determined by surface interpolation of the obtained modal displacements.

\section{NUMERICAL ANALYSIS}

The FEM analysis was performed using ANSYS (R18) software both for static test and modal analysis. Beam was modeled as a shell structure with 1297 elements and 1425 nodes. All elements are SHELL181 type, suitable to analyzing the thin shell structures. The elements have 4 nodes and 6 degrees of freedom at each node [28]. The characteristic element size was $5 \mathrm{~mm}$. The finite element grid and boundary conditions are shown in Fig. 8. for the static test and in Fig. 9. for the modal analysis.

Finite element method analysis conducted using ANSYS Composite Prep/Post (ACP) gives the information about each layer strain. This data was used for comparison of strain measurements in a composite band between the experiment and computer simulation. Additionally, total 
a)

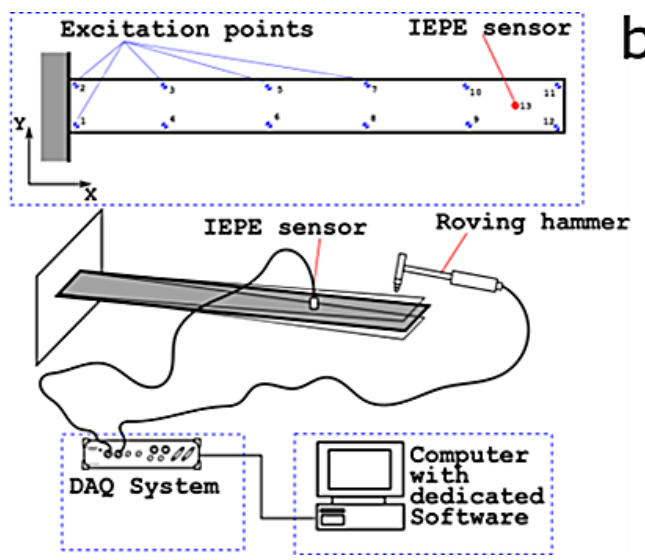

b)

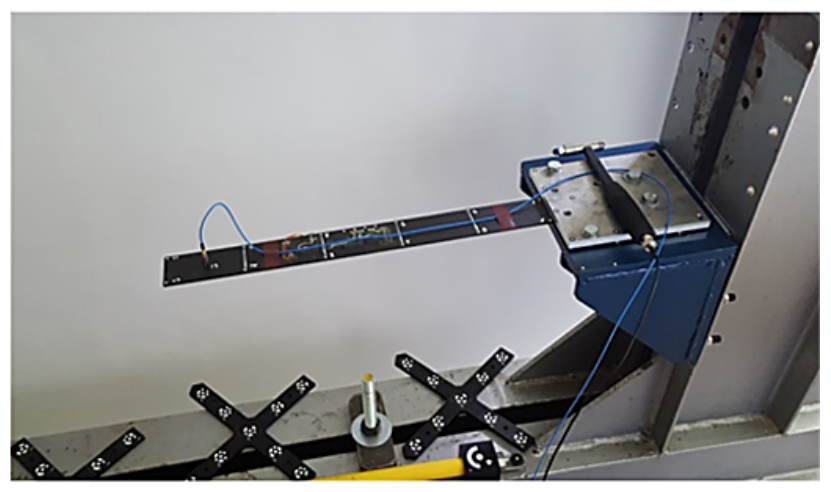

Fig. 6. Schematic of modal test stand (a) and technical realization of a stand (b)

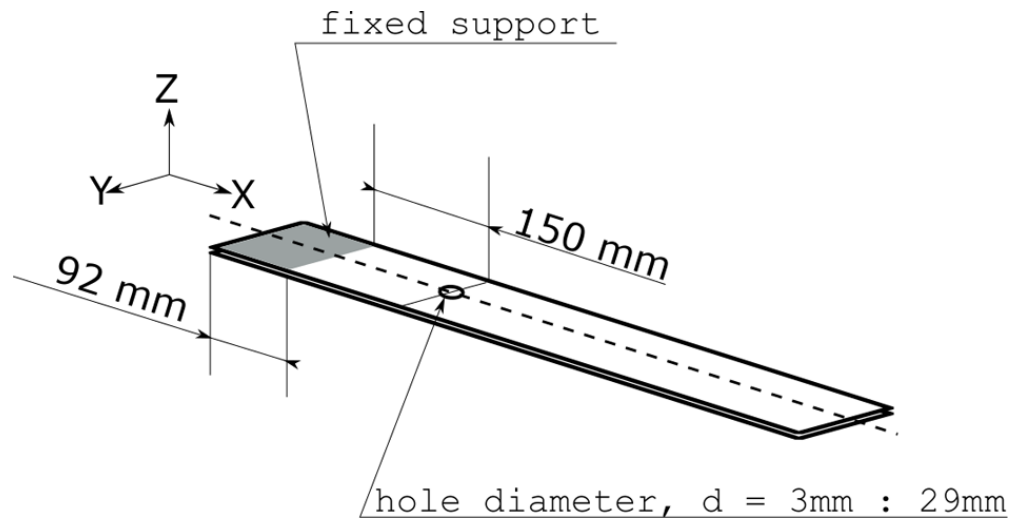

Fig. 7. Schematic of hole location in the band

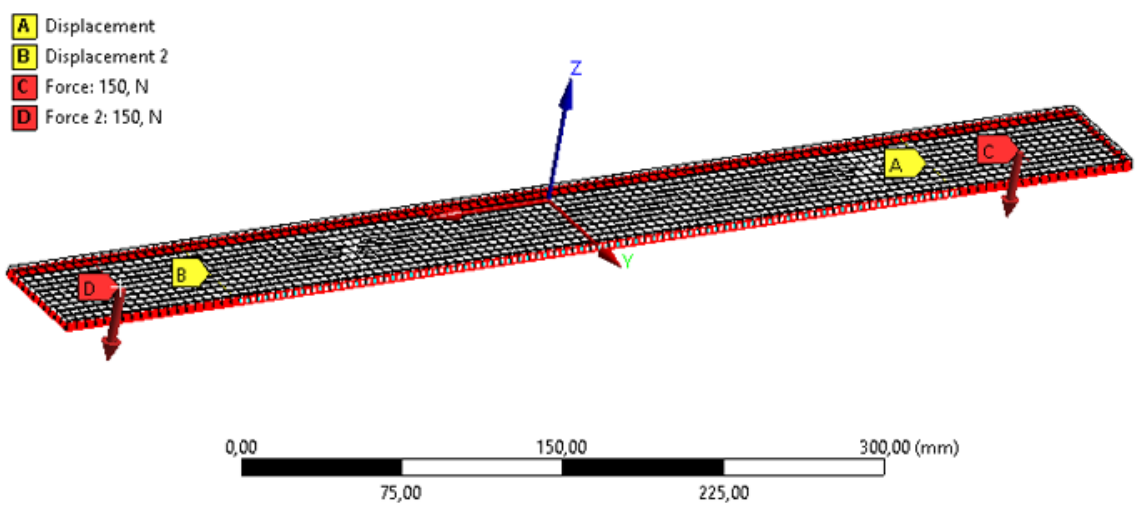

Fig. 8. Finite element grid and boundary conditions for the static test

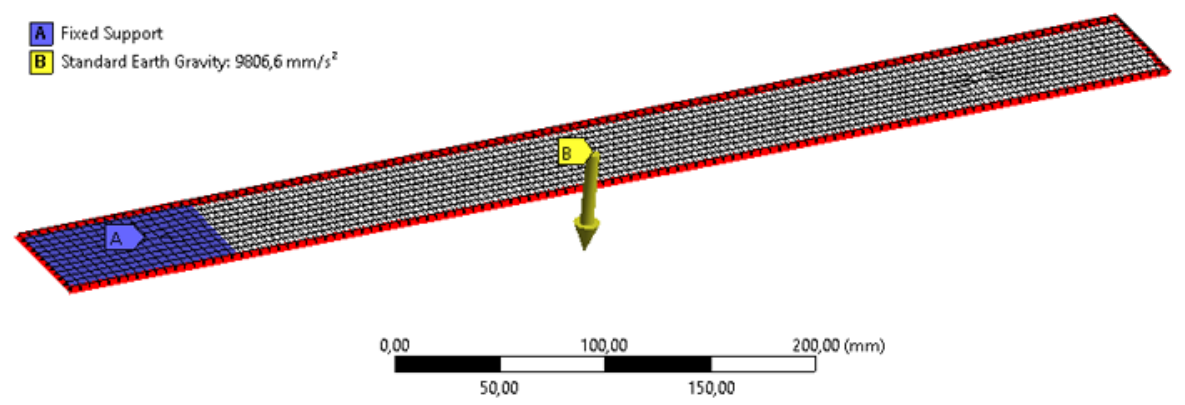

Fig. 9. Finite element grid and boundary conditions for the modal analysis 
deformation of the beam was compared to the deformation measurements during the experimental investigation. The example results are shown in Figure 10.

\section{TEST RESULTS}

\section{Results of test with strain gauges}

They form the basis for assessing the correctness of preparing the system for testing by comparing the degree of compliance with the results of numerical calculations. The possible occurrence of quantitative changes in the measured deformations will prove a change in the local rigidity of the system caused by the structural damage.

Figure 11, presents the dependence of deformation in relation to the applied bending moment for individual layers in which strain gauges are built-in. This graph contains both the results obtained through the experiment and those obtained as a result of numerical analysis. On its basis, it can be concluded that there is a qualitative agreement between the experimental and numerical results. The graph also shows the trend lines illustrating a linear change in strain as a function of the applied load. The dashed line refers to the results of the experiment, whereas the solid line shows the trend for the results of numerical analysis. In Table 2, the quantitative comparison of the obtained results is presented. A noticeable shift in the deformation values measured in the experiment compared to the FEM analysis in the 5th and 13th layers probably results from the fact that the thickness of the obtained composite layers varies, which the FEM model did not take into account.

The difference between the results obtained through the experiment and numerical analyses is expressed by the formula:

$$
\overline{\Delta_{\varepsilon}}=\frac{\varepsilon_{E X P}-\varepsilon_{F E M}}{\varepsilon_{E X P}} \cdot 100 \%
$$

From the results presented in Fig. 11. it follows that any change in stiffness in the examined area due to damage will be noticeable in the shape of the appropriate characteristics, indicating the location of the damage zone.
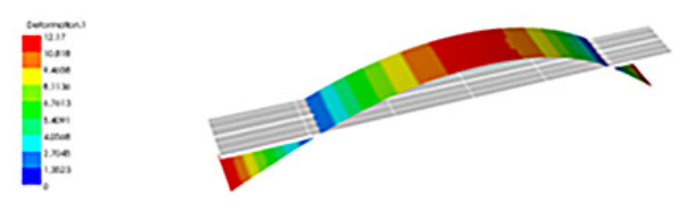

mater
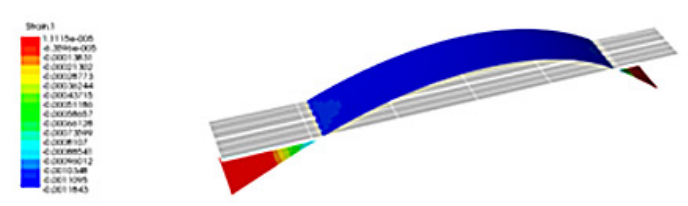

mines

Fig. 10. Deformation of beam (a) and strain in the outside layer of beam (b)

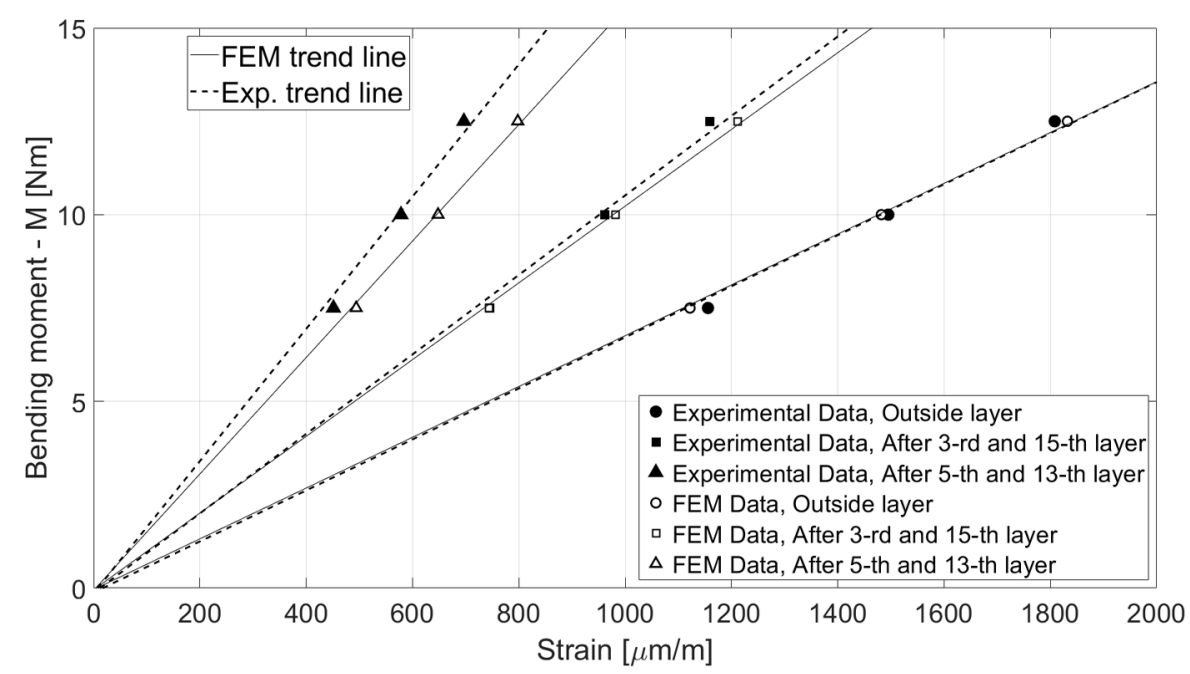

Fig. 11. Strain due to applied bending moment in composite layers (experimental and FEM results) 
Table 2. Comparison of longitudinal elastic strain measured during the experiment and calculated using FEM

\begin{tabular}{|c|c|c|c|}
\hline \multirow{2}{*}{ Layers } & \multicolumn{3}{|c|}{ Longitudinal Elastic Strain $[\mu \mathrm{m} / \mathrm{m}]$} \\
\hline & Experiment & FEM & $\overline{\Delta_{\varepsilon}}[\%]$ \\
\hline \multicolumn{4}{|c|}{ Bending moment $7,5 \mathrm{Nm}$} \\
\hline Outside & 1155,84 & 1122,00 & 2,93 \\
\hline 3-rd and 15-th & 745,74 & 744,00 & 0,23 \\
\hline 5-th and 13-th & 451,26 & 494,00 & $-9,47$ \\
\hline \multicolumn{4}{|c|}{ Bending moment $10 \mathrm{Nm}$} \\
\hline Outside & 1495,04 & 1482,00 & 0,87 \\
\hline 3-rd and 15-th & 961,95 & 982,00 & $-2,08$ \\
\hline 5-th and 13-th & 578,28 & 648,00 & $-12,06$ \\
\hline \multicolumn{4}{|c|}{ Bending moment $12,5 \mathrm{Nm}$} \\
\hline Outside & 1808,19 & 1832,00 & $-1,32$ \\
\hline 3-rd and 15-th & 1159,53 & 1212,00 & $-4,53$ \\
\hline 5-th and 13-th & 696,66 & 798,00 & $-14,55$ \\
\hline
\end{tabular}

The presented analysis is limited to indicating the possibilities of the methodology, without raising a number of significant problems that may constitute significant restrictions in the application, such as the technological issues related to the preparation of the system for research. The application possibilities of the methodology seem to be conditioned to a significant extent by the experimenter's experience.

\section{Modal analysis results}

The analysis of the results obtained from the modal studies was carried out in two stages. First, the correctness of the FEM model was verified with experimental data for an undamaged band. A quantitative comparison of the natural frequencies obtained by means of an experiment and numerical analyses is illustrated in Tab. 3. This table also shows the relative difference between these frequencies. The differences were determined from the relationship:

$$
\Delta_{f}=\frac{f_{E X P}-f_{F E M}}{f_{E X P}} \cdot 100 \%
$$

The largest error was recorded for the third bending mode and it amounted to $5.44 \%$. This indicates that the stiffness of the tested band was greater than assumed in the numerical model. The qualitative assessment was made by comparing the mode shapes obtained in the experiment and numerical analysis. The comparison is presented for the selected natural frequencies in Figures 12 to 15 .

On the left side of each figure there are the values of the relative modal displacement recorded experimentally in relation to the non-vibrating band. An analogous representation of the results obtained in the FEM analysis is shown on the right. These results were imported from the ANSYS and processed in the MatLab software for better comparison. The figures also show the location of the nodal lines of the individual modes (bottom of each figure). It can be stated that in terms of the qualitative comparison, the obtained results show compliance.

The second stage was the analysis of the impact of damage presence and magnitude of this damage on the measured parameters. At this stage, the compliance of numerical calculations with the experiment was verified as well.

The obtained results of the analysis are shown in Fig. 16. The graph shows the MIF value relative to the frequency for the undamaged band and the band with different hole sizes. Additionally, for better readability, selected frequencies are enlarged (upper part of Fig. 16). The presentation of modes with higher frequencies was deliberately abandoned, due to the fact that they present the same nature of changes as those already presented. The conducted experiment shows that the natural frequencies, as expected, change their value as a result of damage. In most cases, this

Table 3. Quantitative comparison of natural frequencies from experiment and FEM simulation

\begin{tabular}{|c|c|c|c|c|}
\hline \multirow{2}{*}{ Mode number } & \multirow{2}{*}{ Type of mode } & \multicolumn{2}{|c|}{ Natural frequency [Hz] } & FEM \\
\cline { 3 - 5 } & & Experiment & 12,90 & 1,68 \\
\hline 1 & Bending & 13,12 & 80,80 & 4,07 \\
\hline 2 & Bending & 84,23 & 121,75 & 1,01 \\
\hline 3 & Twisting & 122,99 & 226,24 & 5,44 \\
\hline 4 & Bending & 239,26 & 373,32 & 2,60 \\
\hline 5 & Twisting & 383,30 & 443,51 & 5,20 \\
\hline 6 & Bending & 467,83 & 647,88 & 2,57 \\
\hline
\end{tabular}



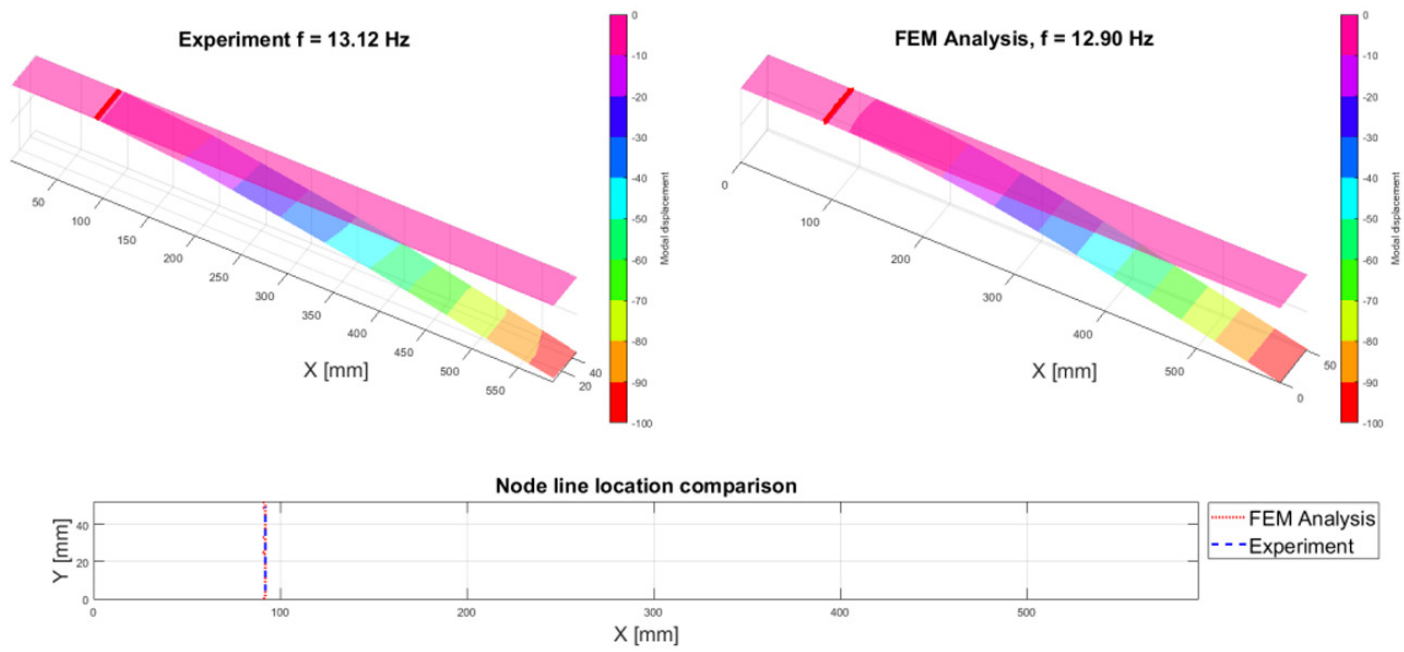

Fig. 12. Comparison of mode shape for First Bending mode of CFRP beam.

Experimental data (left), FEM Analysis (right), Nodal line location (bottom)
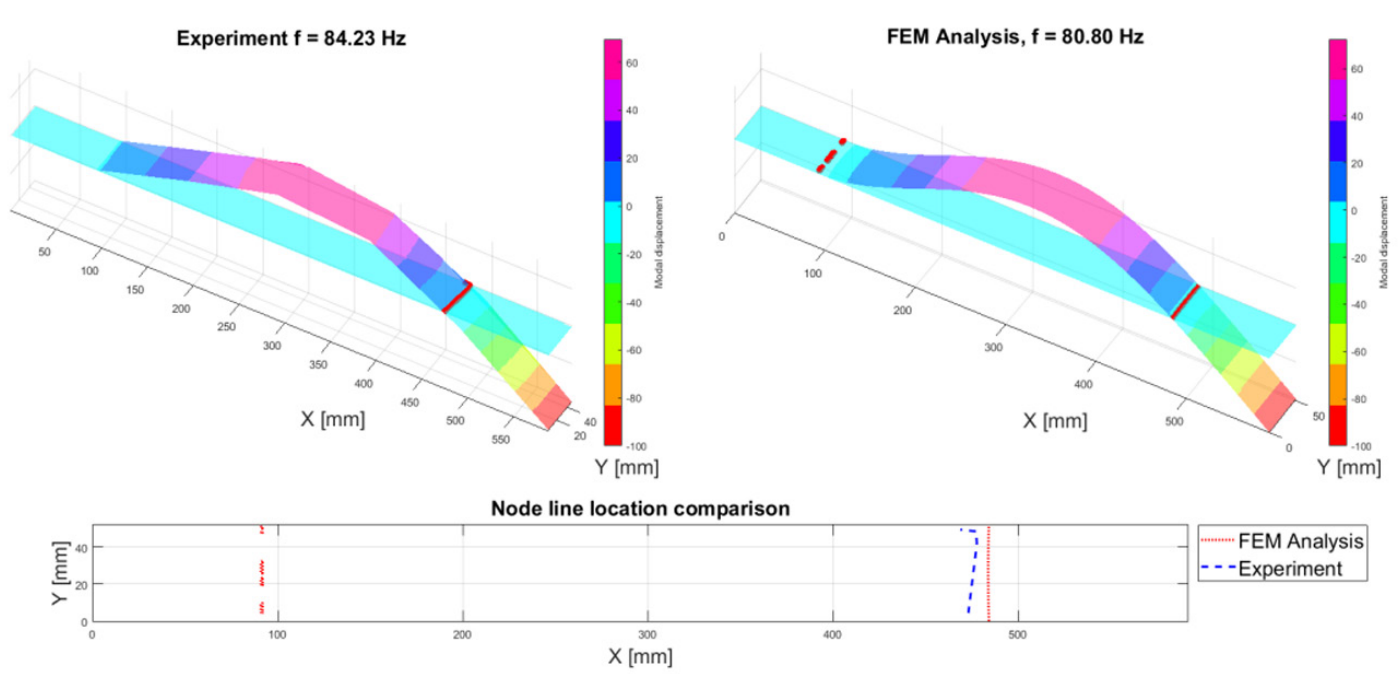

Fig. 13. Comparison of mode shape for Second Bending mode of CFRP beam. Experimental data (left), FEM Analysis (right), Nodal line location (bottom)
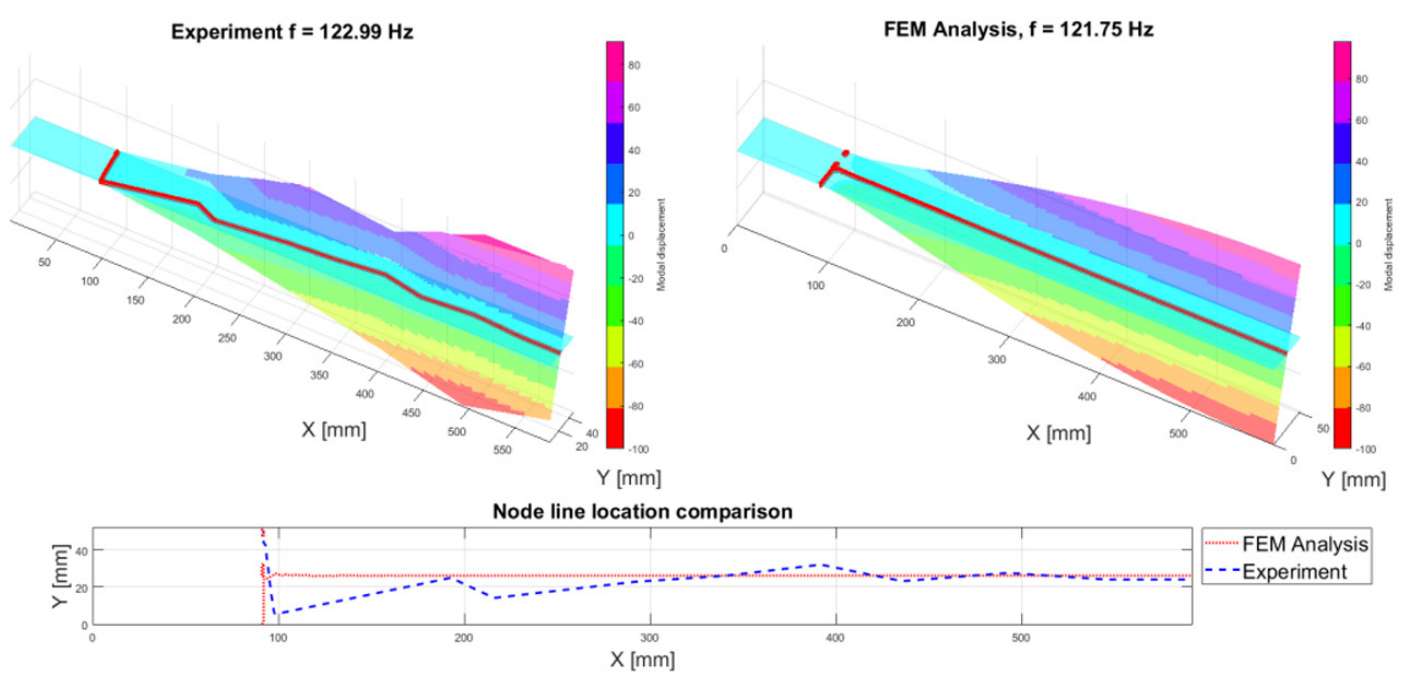

Fig. 14. Comparison of mode shape for First Twisting mode of CFRP beam. Experimental data (left), FEM Analysis (right), Nodal line location (bottom) 


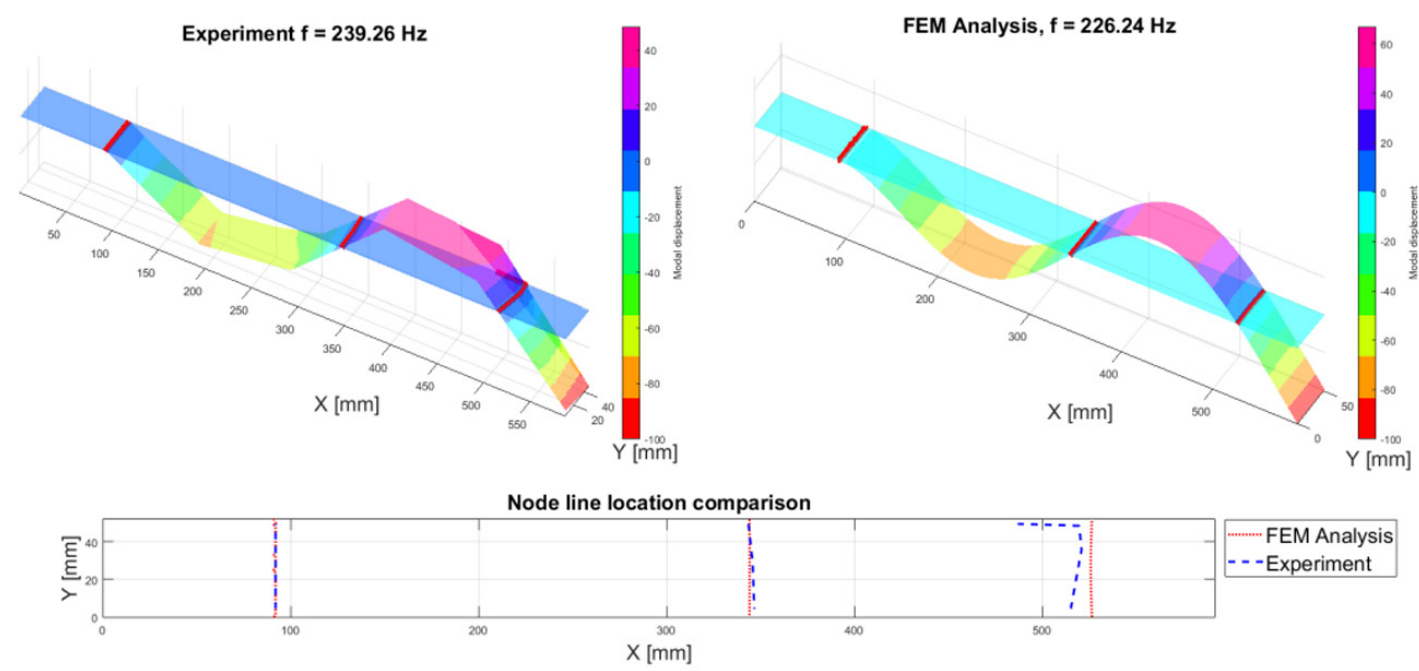

Fig. 15. Comparison of mode shape for Third Bending mode of CFRP beam. Experimental data (left), FEM Analysis (right), Nodal line location (bottom)

is a reduction in frequency with an increase in "damage", for example this can be seen, in modes $2,4,8,10$. In the case of twisting modes, the frequency can be observed to remain at a comparable level or have a small increase in comparison to the undamaged band. It is also interesting that the first twisting mode (described in the chart as Mode \# 3) obtained in both the experiment and numerical analysis for an undamaged band, is not recorded experimentally after the damage occurs. The reason for this appears to be the location of the acceleration sensor during the experiment, as indicated by the low MIF value recorded for this frequency when the band was intact. The registered natural frequency values for the undamaged and damaged band are summarized in Table 4 .
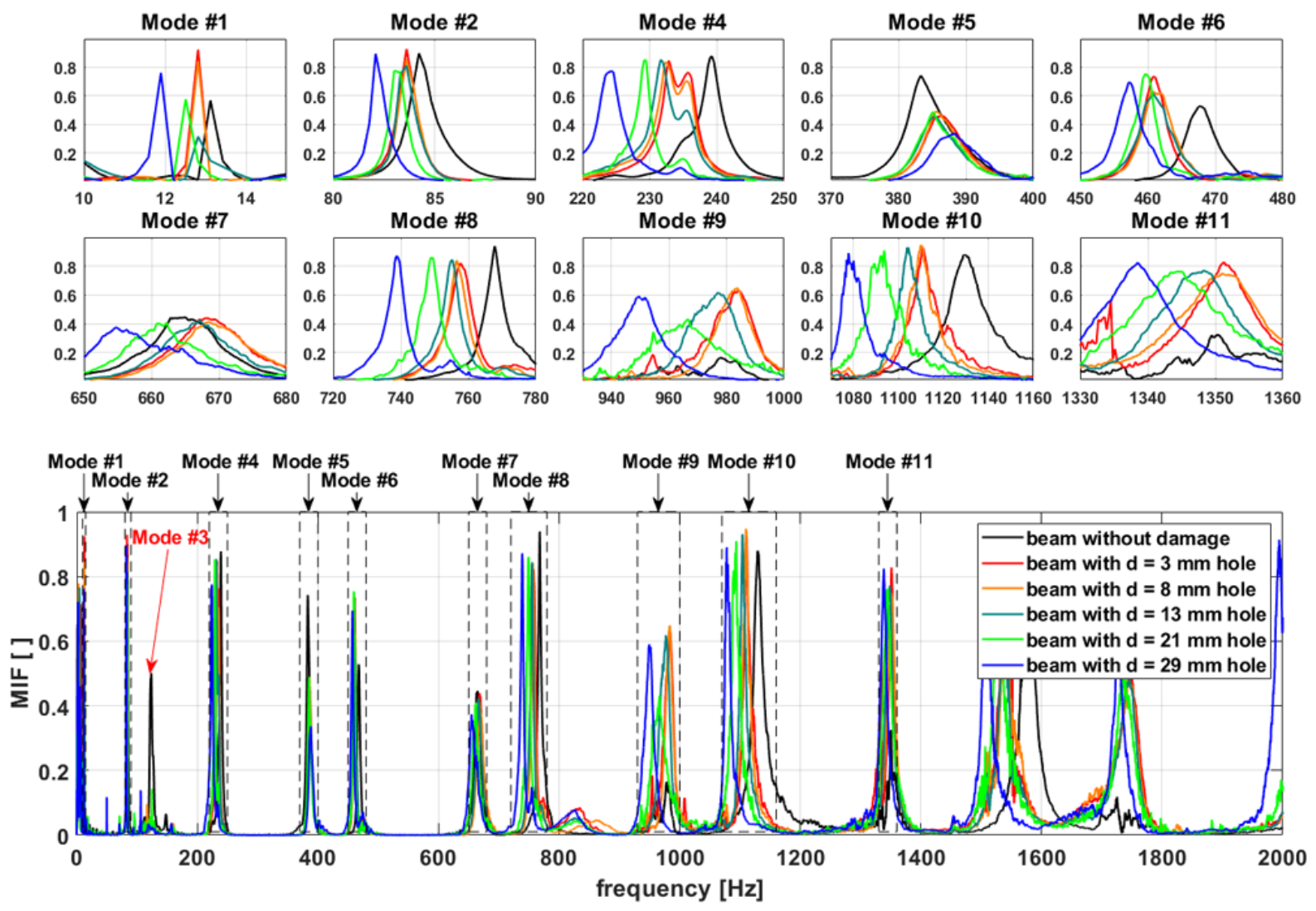

Fig. 16. Comparison of frequencies change due to hole size 
In order to better illustrate the change in individual frequencies as a result of "damage", they are presented as relative values related to the frequency of the intact reference band. Similarly, the hole diameter $d$ is presented as a relative value related to the plate band width B. A similar approach was used for the numerical analysis taking into account damage. These results are compared in Fig. 17 for the selected modes from Mode \# 1 to Mode \# 9, excluding Mode \# 3.

The obtained results show the qualitative agreement between the experiment and the numerical analysis (cf. modes 1, 4, 5, 6, 8). It can be seen that the frequency changes are non-linear, and they are more prominent the greater the damage (hole) is.

\section{CONCLUSIONS}

The paper examines the problems of choosing the research methodologies to determine the presence of local damages that arise during the operation of the composite thin-walled structures. The extent and geometry of the damage suggest using the methods that lead to determining the presence of damage as soon as possible. Out of the two methods analyzed, the modal method seems to be promising and worth recognizing more precisely. The exceptional simplicity in use, the speed of testing, and finally the possibility of testing the system under almost all conditions are clear arguments for continuing further research.

As part of the research, a number of results were obtained to identify the occurrence of damage in the analyzed composite band structure. At the same time, they constituted the basis for the verification of the numerical model. It should be noted that the numerical analysis does not take into account certain factors that are inseparable from the experiment. The FEM analysis is a simplified tool because it is based on an idealized model of the real system. As an example, the infinite rigidity of the support method and manufacturing imperfections can be mentioned.

While the conducted research indicates the possibility of identifying the occurrence of damage in the structure, it is necessary to critically approach such aspects as precise localization of this damage or its shape. The problem of identifying relatively small damages remains open and requires further research, which is suggested by the obtained results.

All considerations related to the methodology used to identify the damage in the thin-walled composite systems require further research.

\section{REFERENCES}

1. Aloisi, S., U. Galietti, and C. Pappalettere. Strain measurement in composite materials using embedded strain gauges. Key Engineering Materials, 1997: 251-260.

2. Arbocz, J. Post-buckling behavior of structures. Numerical techniques for more complicated structures. In Lect. Notes Phys. 1985.

3. Bakunowicz, J., T. Kopecki, T. Lis, and P. Mazurek. Effect of stiffeners on nature of post-critical deformations of thin-walled composite aircraft structures: A combined numerical-experimental study. 2016 7th International Conference on Mechanical and Aerospace Engineering (ICMAE), 2016.

Table 4. Change in natural frequencies due to hole dimensions. Experimental data

\begin{tabular}{|c|c|c|c|c|c|c|}
\hline \multicolumn{7}{|c|}{ Hole dimensions } \\
\hline \multirow{2}{*}{$\mathrm{d}[\mathrm{mm}]$} & \multirow{2}{*}{$\begin{array}{c}\text { no damage } \\
\text { case }\end{array}$} & $\varphi 3$ & $\varphi 8$ & $\varphi 13$ & $\varphi 21$ & $\varphi 29$ \\
\cline { 3 - 7 } $\mathrm{d} / \mathrm{B}[\%]$ & 5,71 & 15,24 & 24,76 & 40 & 55,24 \\
\hline Mode number & \multicolumn{7}{|c|}{ Frequency - $\mathrm{f}[\mathrm{Hz}]$} \\
\hline 1 & 13,12 & 12,82 & 12,82 & 12,82 & 12,51 & 11,90 \\
\hline 2 & 84,23 & 83,62 & 83,62 & 83,62 & 83,01 & 82,09 \\
\hline 3 & 122,90 & - & - & - & - & - \\
\hline 4 & 239,26 & 232,85 & 232,54 & 231,63 & 229,19 & 224,30 \\
\hline 5 & 383,30 & 386,35 & 385,74 & 385,44 & 385,13 & 388,49 \\
\hline 6 & 467,83 & 460,82 & 460,82 & 460,82 & 459,59 & 457,15 \\
\hline 7 & 664,98 & 668,33 & 668,33 & 667,11 & 662,23 & 654,91 \\
\hline 8 & 767,82 & 757,75 & 756,53 & 755,31 & 748,90 & 738,83 \\
\hline 9 & 978,09 & 984,19 & 983,89 & 976,87 & 966,49 & 949,40 \\
\hline 10 & 1128,85 & 1111,15 & 1109,92 & 1104,43 & 1093,75 & 1077,88 \\
\hline 11 & 1350,40 & 1351,32 & 1351,01 & 1348,27 & 1344,30 & 1338,50 \\
\hline
\end{tabular}



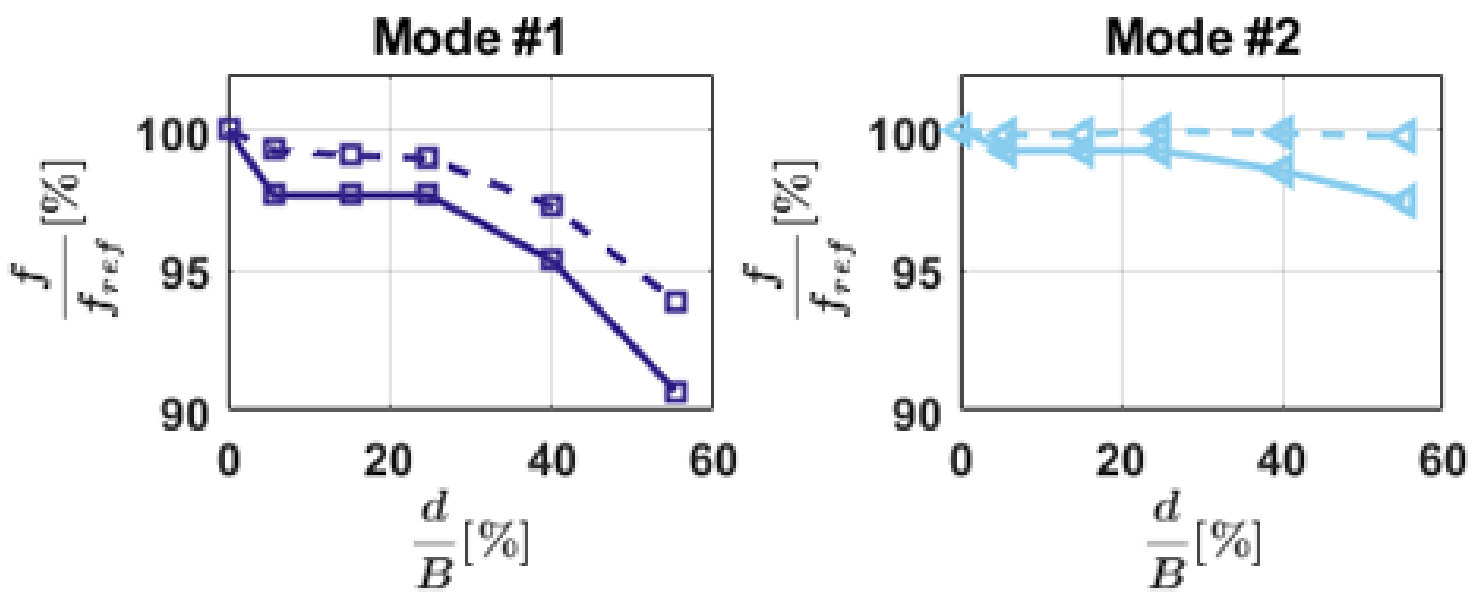

Mode \#4
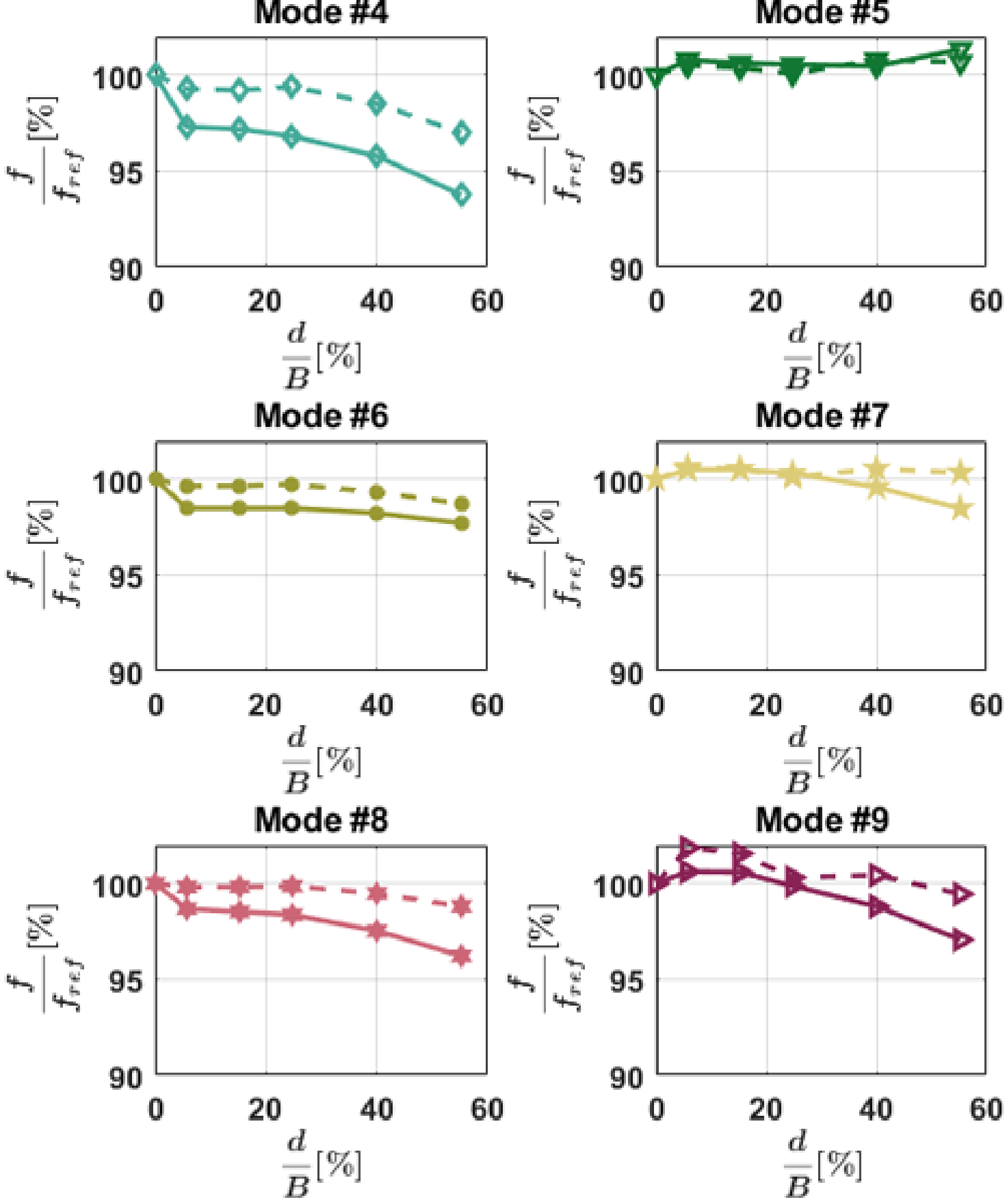

Fig. 17. Comparison of frequency change obtained in the experiment (solid line) and FEM analysis (dashed line) 
4. Belhouideg, S., and M. Lagache. Effect of embedded strain gage on the mechanical behavior of composite structures. Journal of Modern Materials, 2017.

5. Neha, C., Martinez-Sanchez, M., Soutis, C., and Gresil, M. Early damage detection in composites by distributed strain and Acoustic Event Monitoring. Procedia Engineering, 2017.

6. Diamanti, K., and C. Soutis. Structural health monitoring techniques for aircraft composite structures. Prog. Aero. Sci., 2010, 46(8) ed.

7. Døssing, Ole. Structural Testing. Part II: Modal Analysis and Simulation. Brüel\&Kjær, 1988.

8. Doyle, J.F. Nonlinear Analysis of Thin-Walled Structures. Luxembourg: Springer, 2001.

9. Ewins, D.J. Modal Testing: Theory, Practice and Application. Wiley, 2009.

10. Hatch, Michael R. Vibration Simulation Using MATLAB and ANSYS. Chapman and Hall, 2000.

11. Hoffmann, K. An Introduction to Stress Analysis using Strain Gauges. Hottinger Baldwin Messtechnik $\mathrm{GmbH}, 1987$.

12. Jones, R. Mechanics Of Composite Materials, 2nd ed. Philadelphia, PA, USA: Taylor \& Francis, 1999.

13. Kopecki, T., J. Bakunowicz, and T. Lis. Post-critical deformation states of composite thin-walled aircraft load-bearing structures. Journal of Theoretical and Applied Mechanics, 2016, 54 (1) ed.: 195-204.

14. Kopecki, T., P. Mazurek, and T. Lis. Experimental and Numerical Analysis of a Composite ThinWalled Cylindrical Structures with Different Variants of Stiffeners, Subjected to Torsion. Materials, 2019, 19 ed.

15. Kopecki, T., T. Lis, and P. Mazurek. Post-critical deformation of thin-walled load-bearing aircraft structure representing fragment of the one-way torsion box. Advances in Science and Technology Research Journal, 2018, 3 ed.: 203-209.

16. Kopecki, T., T. Lis, P. Mazurek, and J. Bakunowicz. Buckling Deformation of Thin Layer Coverings of Small Curvatures Used in Aircraft Construction. Advances in Science and Technology Research Journal, 2018, 1 ed.: 293-302.
17. Kucharski, T. System pomiaru drgań mechanicznych. Warszawa: WNT, 2002.

18. Liang, K., Q. Sun, and Y. Zhang. Nonlinear buckling analysis of variable stiffness composite plates based on the reduced order model. Compos. Struct., 2018, 206 ed.

19. Mamalis, A.G., D.E. Manolakos, G.A. Demosthenous, and M.B. Ioannidis. Crashworthiness of Composite Thin-Walled Structures. CRC Press, 2019.

20. Niu, M.C. Composite Airframe Structures, 3rd ed. Hong Kong: Conmilit Press Ltd., 2010.

21. Orkisz, M., Ł. Święch, and J. Zacharzewski. Fatigue tests of motor glider wing's composite spar. Eksploatacja i Niezawodność - Maintenance and Reliability, 2012, 14 (3) ed.

22. Quinn, D., A. Murphy, W. McEwan, and F. Lemaitre. Stiffened panel stability behaviour and performance gains with plate prismatic sub-stiffening. Thin Walled Struct., 2009, 47 ed.

23. Schaaf, K., B. Cook, F. Ghezzo, A. Starr, and S. Nemat-Nasser. Mechanical properties of composite materials with integrated embedded sensor networks. Smart Structures and Materials, 2005.

24. Skopinski, T., W. Aiken, and W. Huston. Calibration of strain-gauge installation in aircraft structures for the measurements of flight loads. NASA Technical Report, 1953.

25. Święch, Ł. Experimental and Numerical Studies of Low-Profile, Triangular Grid-Stiffened Plates Subjected to Shear Load in the Post-Critical States of Deformation. Materials, 2019, 12 ed.

26. Takeda, S., Y. Aoki, T. Ishikawa, N. Takeda, and H. Kikukawa. Structural health monitoring of composite wing structure during durability test. Comp. Struct., 2007, 79(1) ed.

27. Wysmulski, P., H. Dębski, P. Różyło, and K. Falkowicz. A study of stability and post-critical behavior of thin-walled copmposite profiles under compression. Eksploatacja i Niezawodność - Maintenance and Reliability, 2016, 18 (4) ed.

28. Theory Reference for the Mechanical APDL and Mechanical Applications. ANSYS, Inc., 2009. 